\title{
PERANCANGAN GRAFIS KEMASAN MAKANAN BURAYOT SEBAGAI OLEH-OLEH KHAS GARUT
}

\author{
Egi Anwari ${ }^{1}$, Ella Meilani' ${ }^{2}$ Oktarina Prasetyowati ${ }^{3}$ \\ ${ }^{1,2,3}$ Dosen Desain Komunikasi Visual \\ Institut Teknologi Harapan Bangsa (ITHB) \\ 1egi@ithb.ac.id, ${ }^{2}$ ella@ithb.ac.id, ${ }^{3}$ oktarina@ithb.ac.id
}

\begin{abstract}
Abstrak. This research was made to redesign the packing of Burayot, a typical snack from Garut. Food packaging, in addition to serving as a food protector, can also be a medium for communicating related food product information, brand, positioning and product differentiation. Burayot is a typical snack of Garut made from raw rice flour, brown sugar and coconut milk. In its development appeared other flavors, such as pandanus, black rice, menthol, strawberries, sesame and cheese. Generally, families in the area of Leles Garut can make burayot, but not every family sells it as commercial product. There are some small medium enterprises (SME) that produce burayot as commercial snack with different brands, such as Mak Ijoh, Saboga and Bu Lilis. However, those SMES haven't made packaging design as one of their concern in doing their business, yet. Saboga has fairly good sales distribution, the products can be easily found in several gift shops in Garut and Bandung. But, as mentioned before, this brand has not been considering the packaging design. Its packaging hasn't shown strong visual identities to distinguish it from other products, and it also hasn't contained information needed for a packaging.
\end{abstract}

This research method is qualitative by using experimental approach in the form of packaging design through design stages, visual studies and visual styling. Several trials of packaging materials are constrained by the content of cooking oil in the burayot confectionery that is widely absorbed in paper materials. The addition of paper material to the packaging structure has not been successful, so the experiment focuses more on the packaging label appearance.

The results of this study are expected to help SME producers, especially Sabay burayot snacks can have packaging with a strong identity and clear information, so that consumers are easier to distinguish with other gifts.

Keywords: kemasan makanan, label kemasan, penganan burayot, rupa kemasan

Relevance to Visual Communication Design Practice: Desain kemasan memiliki peranan penting dalam bidang pemasaran produk. Perancangan grafis untuk kemasan ini dapat membangun branding, positioning dan diferensiasi produk, sehingga dapat memberikan nilai tambah produk sekaligus menaikkan citra produk di benak masyarakat. Hal ini sekaligus dapat berpengaruh pada penjualan produk khususnya di sektor UKM.

\section{PENDAHULUAN}

Indonesia memiliki kekayaan bahan baku pangan, sehingga variasi makanan yang ada sangat beragam. Setiap daerah memiliki jenis pangan khas masing-masing. Budaya membawa oleh-oleh atau buah tangan kemudian memicu setiap daerah untuk memproduksi penganan khas daerah, yang utamanya ditujukan kepada orang-orang yang mengunjungi daerah tersebut, sehingga mereka bisa membelinya untuk dibawa pulang ke daerah masing-masing. Pada umumnya, produksi makanan oleh-oleh 
tersebut digerakan oleh para pelaku sektor UKM (Usaha Kecil Menengah).

Ketika produk pangan dijadikan komoditas, maka harus dipertimbangkan juga cara mengemasnya, sehingga produk tersebut bisa selamat selama perjalanan. Kemasan menjadi salah satu faktor penting, karena selain melindungi isi, tampilan grafis kemasan yang baik akan meningkatkan nilai produk, sekaligus dapat memperjelas informasi mengenai makanan tersebut, dan memperlihatkan identitas daerah asalnya.

Burayot merupakan salah satu makanan oleh-oleh khas Garut, Jawa Barat. Makanan ini dapat ditemukan di daerah Leles, Kadungora dan Wanaraja. Burayot terbuat dari bahan baku tepung beras, gula aren dan santan, yang adonannya dibuat seperti bola, kemudian dipipihkan dan digoreng. Untuk mengangkat adonan pipih tersebut dari penggorengan, digunakan batang kayu atau bambu yang ditusukkan pada bagian tengah adonan, sehingga hasilnya akan menggelembung ke bawah. Nama burayot ini berasal dari bentuk tersebut, yang dalam bahasa Sunda disebut ngaburayot.

Pada awalnya burayot merupakan makanan khas lebaran, pernikahan atau khitanan, namun pada perkembangannya, burayot kemudian dijadikan makanan oleholeh yang dipasarkan secara komersil oleh para pelaku UKM. Ada beberapa brand burayot yang telah beredar di pasaran, yakni Saboga, Bu Lilis, Ibu Ijoh dan beberapa nama brand lainnya.

Burayot dijual dalam kemasan kecil, sedang dan besar yang berisi rata-rata 22, 40 dan 50 per kemasan. Umumnya bahan yang banyak dipakai untuk kemasan adalah kotak plastik dan besek, seperti yang terlihat pada gambar 1. Bahan kemasan tersebut banyak digunakan karena selain lebih praktis, juga mudah ditemukan di pasar. Faktor lain yang umumnya menjadi alasan produsen UKM adalah harga yang masuk ke perhitungan biaya produksi. Produsen burayot belum sepenuhnya memerhatikan kemasan dalam pemasarannya. Mereka memiliki keterbatasan pemahaman mengenai kemasan, khususnya yang berhubungan dengan desain kemasan dan tampak sudah menjadi hal umum di kalangan pelaku UKM.

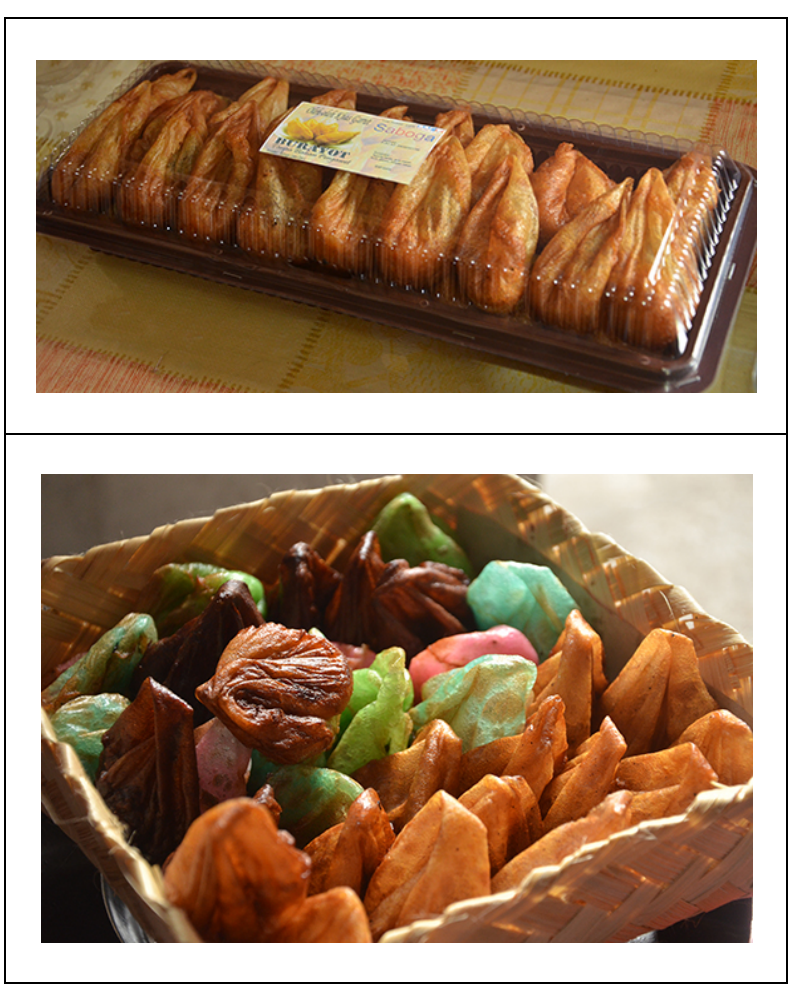

Gambar 1 Kemasan Burayot Saboga dan Bu Lilis (Sumber: dokumentasi peneliti)

Nama burayot terdengar unik dan biasanya mengundang pertanyaan mengenai rasa dan bentuk penganan tersebut. Pengemasan burayot yang terlihat sederhana, bahkan cenderung apa adanya bisa terlihat salah satunya pada label kemasan. Tampilan visual atau rupa grafis pada label kemasan secara umum belum terolah dengan baik. Label kemasan menggunakan bahan kertas 
HVS dan kertas stiker. Label dari kertas HVS biasanya dilindungi dengan plastik untuk menghindari rembesan minyak dari burayot. Hasil dari pengamatan, umumnya ukuran label kemasan terlalu kecil sehingga informasi mengenai produk kurang terbaca. Identitas brand masih belum kuat, sehingga kurang memperlihatkan burayot sebagai penganan oleh-oleh khas daerah Leles Garut, seperti yang terlihat di gambar 2 .

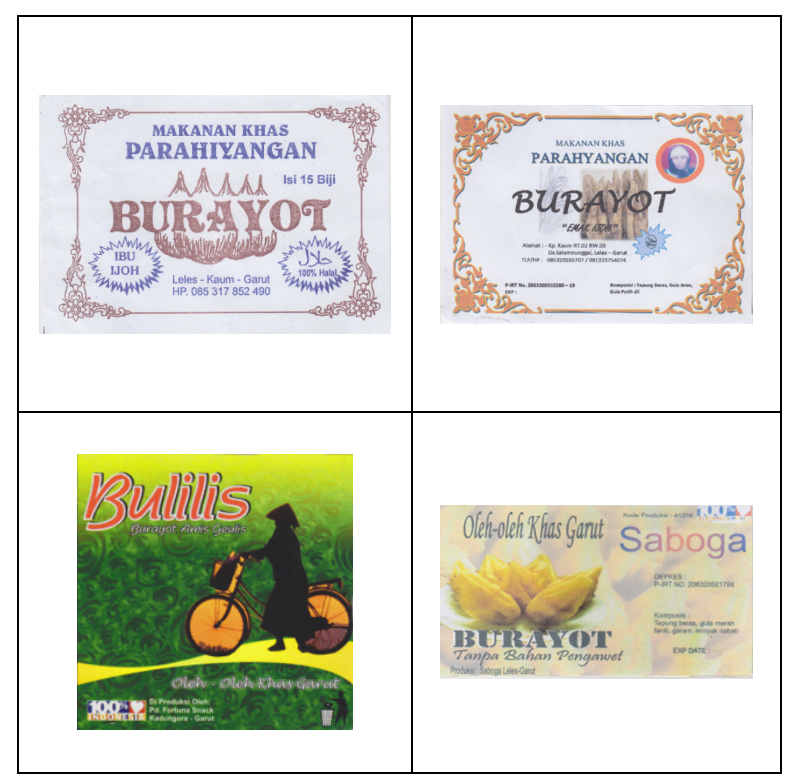

Gambar 2 Sistem labeling Burayot

(Sumber: dokumentasi peneliti)

\section{PROSES PEMBUATAN BURAYOT}

Daerah Leles Garut menjadi sentra perajin penganan burayot, sehingga setiap keluarga di sana umumnya pandai membuat makanan khas ini. Mereka memiliki kebanggan tersendiri bisa mengolah penganan yang proses pembuatannya sederhana. Untuk produksi yang dilakukan oleh UKM seperti brand Saboga dapat menghasilkan sekitar 2200 buah burayot per hari. Bahan-bahan yang diperlukan adalah sebagai berikut:
- $\quad$ Tepung beras Sarinah dan Ciherang yang ditanam di wilayah Garut

- Gula aren (yang dipakai yang berwarna kuning) dari daerah Bungbulang Garut

- Gula putih

- Vanila

Proses pembuatan burayot secara garis besar adalah sebagai berikut: gula aren dan gula putih dicampur, dimasak sampai mencair, lalu disaring. Kemudian dilakukan pemanasan kedua dengan vanilla, lalu ditiriskan. Selanjutnya dimasukkan tepung beras dan diaduk sampai seluruhnya tercampur rata. Setelah itu, adonan didiamkan semalam sampai mengendap. Langkah berikutnya adalah membulatkan adonan, untuk kemudian dipipihkan. Kemudian adonan pipih tersebut dimasukkan ke dalam penggorengan berisi minyak panas dan langsung diangkat setelah berwarna kuning keemasan. Secara detail, proses pembuatan burayot dapat dilihat di gambar 3 .
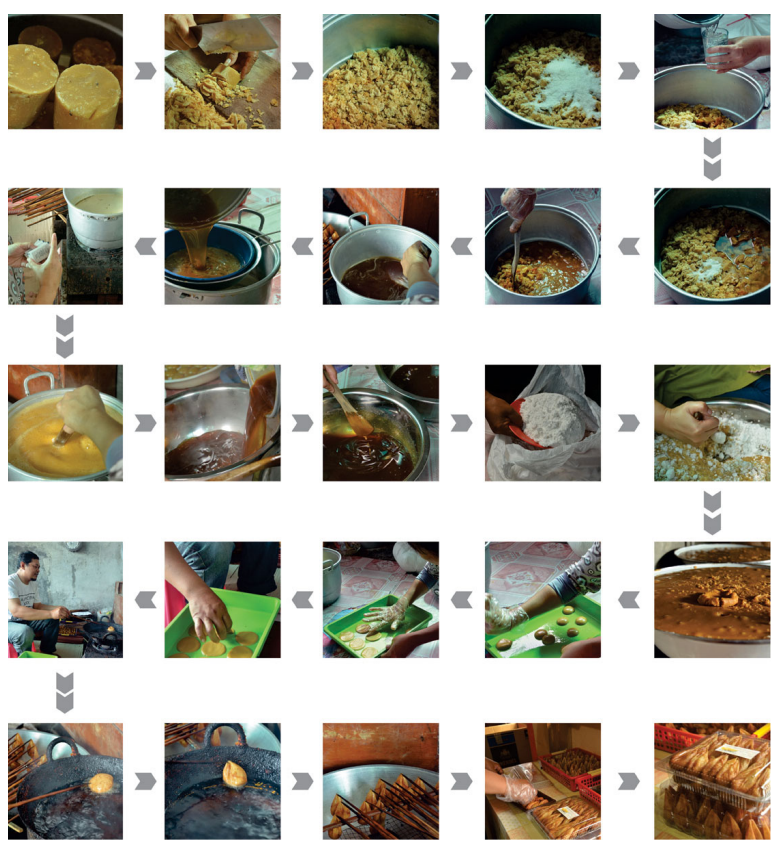

Gambar 3 Proses detail pembuatan burayot (Sumber: dokumentasi peneliti) 
Bentuk menggelayut (bahasa Sunda: ngaburayot) diperoleh dari cara mengangkat penganan dari penggorengan, yakni menusuk bagian tengahnya dengan menggunakan bambu dan diangkat. Setelah itu kemudian ditiriskan sehingga minyaknya turun, seperti yang ditampilkan pada gambar 4 .

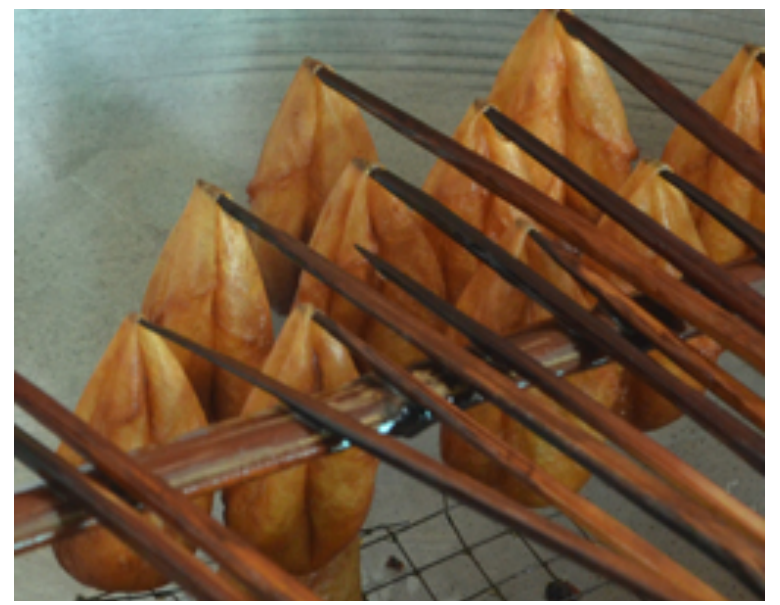

Gambar 4 Burayot yang sedang ditiriskan (Sumber: dokumentasi peneliti)

\section{RUANG LINGKUP PERMASALAHAN}

Brand burayot yang diangkat untuk penelitian ini diambil dari brand Saboga, dengan dasar pemikiran bahwa brand ini telah cukup lama memproduksi burayot dan telah memiliki jaringan distribusi yang baik dengan toko-toko oleh-oleh di Garut dan Bandung. Namun dari sisi kemasan, masih belum dirancang dengan optimal, terutama pada identitas visual dan informasi yang tertera pada label kemasan.

Saboga akan dijadikan pilot project bagi produsen burayot di kawasan Leles Garut untuk menunjukkan bagaimana perancangan kemasan yang baik akan lebih meningkatkan citra brand, sehingga diharapkan akan lebih dikenal luas oleh konsumen dan mampu memiliki daya saing di pasar.

\section{TEORI KEMASAN PANGAN}

Para pelaku UKM umumnya masih belum memprioritaskan faktor desain kemasan dalam upaya mengangkat nilai dari brand yang dimilikinya. Biasanya pelaku UKM lebih fokus pada masalah keterbatasan modal, faktor SDM, pemasaran atau akses pasar untuk memasarkan produknya, dan kurang memperhatikan sisi desain kemasan penganan yang akan dijualnya. Menurut Wahyudi dan Satriono (2017:75) ada sebagian pelaku UKM yang sudah tahu akan pentingnya desain kemasan bagi penjualan produk mereka dan menggarap desain kemasannya dengan baik lewat bantuan biro desain kemasan. Namun pelaku UKM yang lain mempunyai desain kemasan yang biasa saja. Padahal produk penganan UKM banyak yang berkualitas baik.

Masalah desain kemasan bukan hanya soal tampilan rupa saja, melainkan juga pada pemahaman mengenai bahan atau material kemasan. Hal tersebut membuat produsen di kalangan UKM sering memilih material yang kurang tepat. Banyak ditemukan produk makanan dengan kemasan dari bahan kertas karton yang bersinggungan langsung dengan isinya, namun bahan kemasan tidak termasuk dalam kategori food grade (aman untuk produk makanan) sehingga bisa mengontaminasi produknya. Atau pemilihan kemasan standing pouch dengan zipper yang bisa dibuka tutup, tetapi tidak ditambah dengan sealing di atasnya sehingga diragukan kebersihan produknya, karena tiap orang bisa membuka menutup kemasan selama dipajang di rak penjualan.

Ambrose dan Harris (2011:188) memaparkan bahwa pemilihan bahan kemasan harus menjadi pertimbangan karena 
bahan tertentu dihasilkan dari berbagai jenis bahan baku yang dapat menggangu atau merusak lingkungan. Jenis bahan kemasan pangan (makanan) yang banyak dipakai adalah plastik, kertas dan metalizing (sejenis plastik yang diberi lapisan uap alumunium). Menurut Andrianto (2008:44), penggunaan plastik relatif luas karena bahan baku mudah didapat, harga yang murah, mudah dibentuk dan mudah dalam proses distribusi.

Mengenai kualitas desain kemasan Wahyudi dan Satriono (2017:76) menjelaskan umumnya perusahaan besar memiliki dana yang besar untuk membuat atau mendapatkan kemasan yang baik. Namun, tidak berarti bahwa desain kemasan produk UKM yang bermodal kecil pasti akan lebih jelek dibandingkan dengan produk perusahaan besar.

Desain kemasan yang baik dirancang dengan melihat sisi karakter produk serta konsumen yang dituju. Mengetahui secara mendalam kelebihan dan kekurangan produk akan berguna dalam membentuk identitas kemasan yang kuat dan jelas. Merujuk pada Julianti (2017:19), desain kemasan akan melibatkan warna, tampilan grafis, tipografi, struktur bahan, pencetakan dan komunikasi yang ingin disampaikan, dengan penjelasan sebagai berikut:

\section{A. Warna}

Sebuah kemasan harus memiliki kombinasi unik dan menarik yang bisa menunjukkan identitas brand. Pemilihan warna menjadi bagian yang sangat penting. Berdasarkan studi akademis, $80 \%$ pengenalan produk disebabkan oleh warna. Pemilihan warna kemasan juga harus sesuai dengan jenis produk dan kultur budaya setempat.

\section{B. Tampilan Grafis}

Elemen atau unsur dalam tampilan grafis sebuah kemasan berperan dalam memberi kejelasan dan identitas sebuah desain kemasan. Berbagai elemen grafis seperti gambar produk, layout dan tipografi akan memperkaya sebuah kemasan fleksibel.

\section{Tipografi}

Kontras antara huruf dan gambar serta warna menjadi hal yang harus diperhatikan untuk memudahkan dalam membaca teks, terutama informasi mengenai makanan. Berkaitan dengan penataan huruf, menurut Sihombing (2003) jenis huruf, anatomi huruf, karakter huruf, dan citra huruf merupakan elemen dalam pembentukan visualisasi. Setiap huruf memiliki arti, makna dan citra tertentu. Dalam perancangan kemasan makanan oleh-oleh ini pengolahan huruf menjadi bagian yang sangat penting agar konsumen mudah untuk membacanya.

Keseluruhan tampilan visual disatukan dengan memperhitungkan tata letak. Faktor tata letak sebuah kemasan tidak dapat dianggap sama seperti membuat tata letak obyek dua dimensi (Ambrose; Harris: 2011: 184). Perlu memperhatikan ruang tata letak secara keseluruhan, bagian per bagian dengan detil. Tata letak kemasan yang baik dapat menarik perhatian ketika disimpan dalam deretan rak seperti di pasar swalayan.

Kemasan pada dasarnya difungsikan untuk melindungi isi atau produk sehingga menjadi aman dari benturan, tidak terkontaminasi atau tidak cepat basi dalam jangka waktu tertentu. Menurut undangundang RI Nomor 18 Tahun 2012 tentang pangan, kemasan pangan adalah bahan yang digunakan untuk mewadahi dan atau 
membungkus pangan, baik yang bersentuhan langsung dengan pangan maupun tidak. Sedangkan label menurut peraturan Badan Pengawas Obat dan Makanan RI, nomor 12 tahun 2016 tentang pendaftaran pangan olahan adalah keterangan mengenai pangan yang berbentuk gambar, tulisan, kombinasi keduanya, atau bentuk lain yang disertakan pada pangan, dimasukkan ke dalam, ditempelkan pada, atau merupakan bagian kemasan pangan. Penjelasan mengenai informasi apa saja dapat diuraikan sebagai berikut:

\begin{tabular}{|l|l|}
\hline Nama Merek & Komposisi \\
\hline Jenis produk & $\begin{array}{l}\text { Informasi } \\
\text { nilai gizi }\end{array}$ \\
\hline Ijin Depkes & $\begin{array}{l}\text { Customer } \\
\text { care/service }\end{array}$ \\
\hline Berat/isi & Label halal \\
\hline Perusahaan pemroduksi & Kode produksi \\
\hline Perusahaan distributor & Kadaluwarsa \\
\hline Barcode & $\begin{array}{l}\text { Himbauan- } \\
\text { himbauan }\end{array}$ \\
\hline
\end{tabular}

Tabel 1 Informasi dalam kemasan

Merancang struktur kemasan dan tampilan rupa kemasan pangan memerlukan proses yang bertahap. Menurut Klimchuk dan Krasovec (82:2006) dalam desain kemasan, prinsip dasar desain harus disesuaikan untuk memenuhi tujuan setiap bagian desain. Lebih detil lagi Julianti (40-53: 2014), menjelaskan tahap-tahap yang umum dilakukan ketika mendesain kemasan adalah:

1. Idea phase : Proses mendesain tampilan kemasan dimulai dari penggalian gagasan.
Prinsip tahap ini adalah mendorong penyebaran gagasan sehingga membuka lebar-lebar pemikiran kritis dan pemikiran kreatif.

2. Design phase : Tahap desain mengacu pada hasil gagasan yang sudah dipilih dari berbagai alternatif hasil diskusi, yang terbagi atas 3 tahap lagi, yaitu:

a. Conceptual design: Pada tahap ini merupakan proses pembuatan konsep desain. Perencanaan konsep desain kemasan disesuaikan dengan tujuan perancangan. Hasil dari idea phase dikembangkan untuk memilih tematik desain dan bahan kemasan.

b. Embodiment design: Proses desain tahap ini merupakan pengembangan dari konsep yang dipilih. Berbagai kemungkinan struktur kemasan dan tampilan rupa dipertimbangkan, sehingga desain yang sesuai dengan berbagai aspek dapat diuji coba. Studi visual dengan mempertimbangkan bentuk, struktur, tata letak, komposisi, warna, gambar, tipografi dan elemen visual pendukung.

c. Detail design: Pada tahap detail, bentuk, ukuran dan toleransi kemasan ditentukan, serta bagaimana memberi tampilan grafis kemasan yang sesuai dengan hasil studi visual serta penggayaan visual yang telah disesuaikan. Seluruh detil informasi akan terlihat pada tampilan yang diterapkan pada label kemasan.

\section{Feasibility phase}

Pada tahap ini dibuat dummy yang sesuai dengan ukuran 1:1 sehingga dapat dilihat dan dicoba untuk melihat apakah masih ada kekurangan. Penting membuat 
dummy yang baik untuk memperlihatkan fungsi kemasan sesuai dengan produk atau makanan yang menjadi isinya.

\section{Capability phase}

Proses akhir setelah semua diuji coba dan dummy yang sudah disempurnakan dapat diproduksi sesuai dengan kebutuhan. Pada tahap ini proses produksi akan disesuaikan dengan kemampuan biaya yang tersedia.

\section{Launching}

Pada tahap ini hasil kemasan makanan oleh-oleh sudah jadi diproduksi secara masal, dipasarkan dan diterima oleh konsumen yang dituju.

\section{SOLUSI}

Dalam merancang sebuah kemasan untuk produk makanan, ada dua hal yang harus diperhatikan, yakni aspek struktur kemasan dan desain grafis kemasan.

\section{A. Struktur Kemasan}

Untuk struktur kemasan, hal yang harus dipertimbangkan adalah kemampuan melindungi untuk mencegah perubahan bentuk burayot. Selain itu, penganan ini mengandung banyak minyak, sehingga dalam eksperimentasi, pemilihan bahan akan melibatkan bahan yang cocok untuk produk berminyak (Seperti plastik atau kertas minyak).

\section{B. Grafis Kemasan}

Untuk desain grafis kemasan, ada dua alternatif kelompok kata kunci yang nantinya akan dipakai untuk menghasilkan dua tipe visual yang berbeda untuk kemasan burayot.

Ada pun dua kelompok kata kunci tersebut adalah :

1. Klasik, tradisional, manis, santai
Kelompok kata kunci pertama ini diambil dari kecamatan Leles (dari daerah asal burayot), turun-temurun, beras (sebagai bahan baku burayot), manis (dari rasa burayot) dan sederhana (dari teknologi pembuatan burayot).

2. Modern, casual, manis

Kata modern diambil berdasarkan pertimbangan untuk mengubah positioning burayot, sehingga tidak kalah dengan produkproduk penganan yang dihasilkan oleh industri besar makanan. Casual (santai) untuk menyatakan bahwa produk burayot ini adalah penganan ringan yang bisa dinikmati oleh siapa pun dan kapan pun, dalam suasana santai. Sementara kata manis, diambil dari rasa burayot.

\section{REFERENSI KEMASAN}

\section{A. Struktur Kemasan}

Sumber gagas untuk struktur kemasan yang memiliki spesifikasi melindungi seperti yang telah dirumuskan sebelumnya ditampilkan dalam gambar 5 .
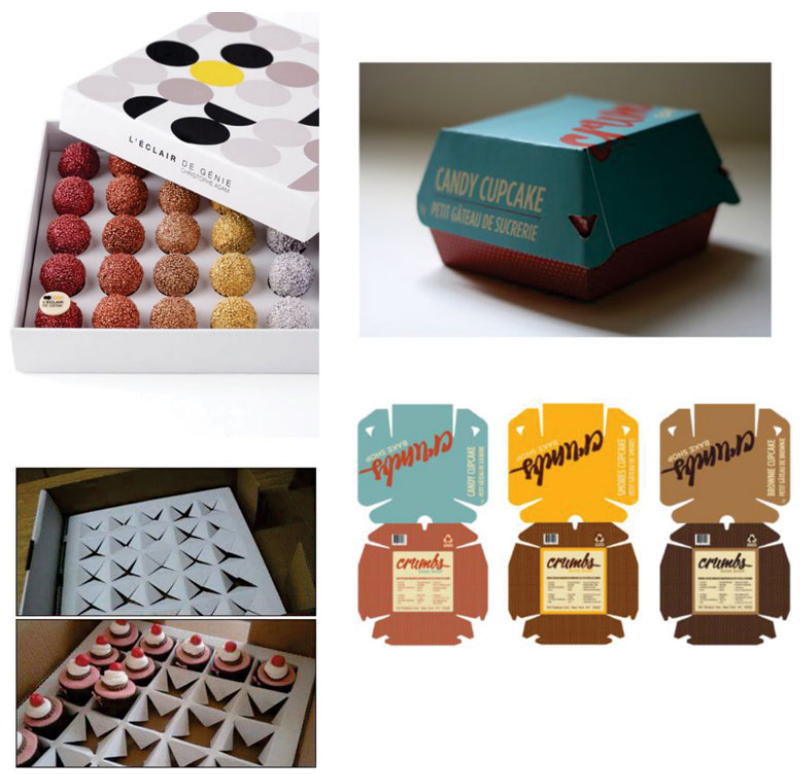

Gambar 5 Sumber gagas struktur kemasan (berbagai sumber) 


\section{B. Tata letak}

Referensi tata letak untuk tampilan grafis kemasan ditampilkan dalam gambar 6 .
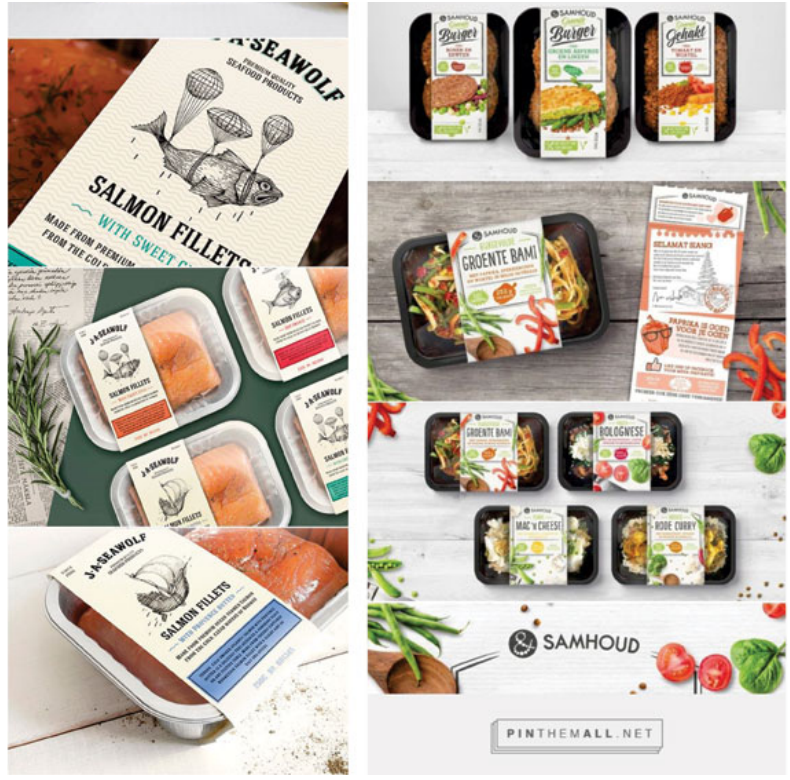

Gambar 6 Sumber gagas tata letak kemasan (sumber : berbagai sumber)

\section{Logotype}

Kesan sederhana dan tradisional menjadi acuan dalam pengolahan tipografi. Unsur handwriting menjadi dominan dalam pengolahan huruf. Paduan antara kesederhanaan dan citarasa tradisional menjadi ciri khas pada logotype burayot Saboga, seperti yang ditampilkan dalam gambar 7.

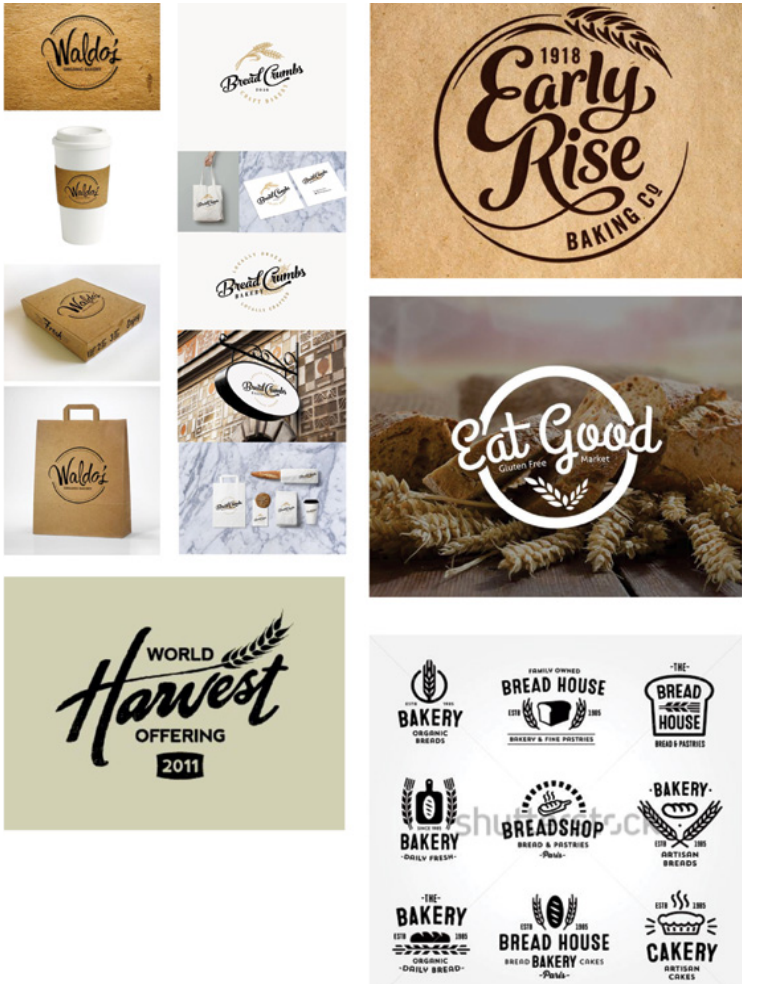

Gambar 7 Sumber gagas penggayaan visual logotype (sumber : berbagai sumber)

\section{Maskot}

Untuk kelompok kata kunci tradisional, akan memunculkan maskot bersumber gagas dari rupa perempuan Sunda kuno, seperti yang ditampilkan di Gambar 8.

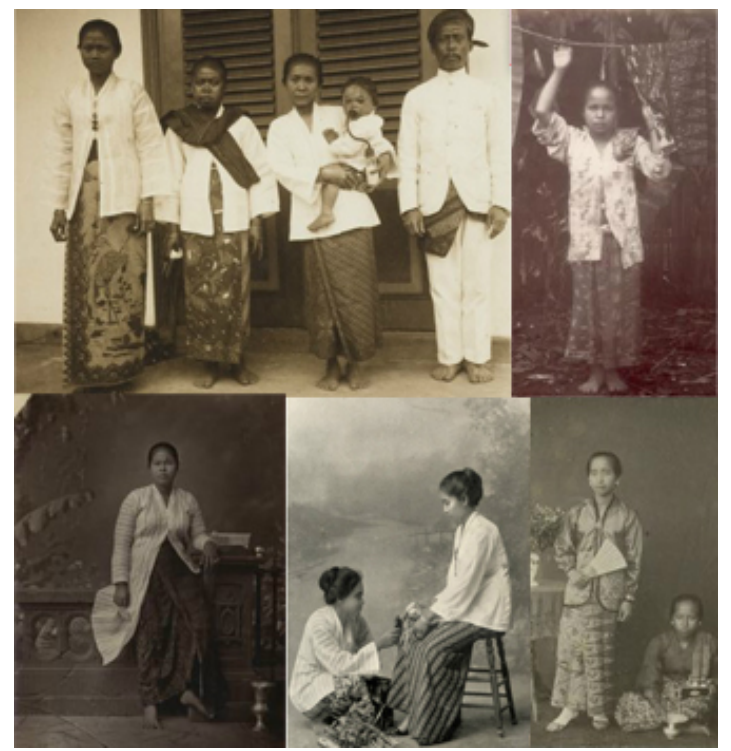

Gambar 8 Referensi Maskot Perempuan Sunda (Sumber: media-kitlv.nl) 


\section{STUDI VISUAL}

Color Mood

Untuk Citra tradisional, manis, santai. Pada label akan muncul warna yang berkesan tradisional dan sederhana dengan paduan warna utama dan warna pendukung, seperti yang ditampilkan pada gambar 9 .

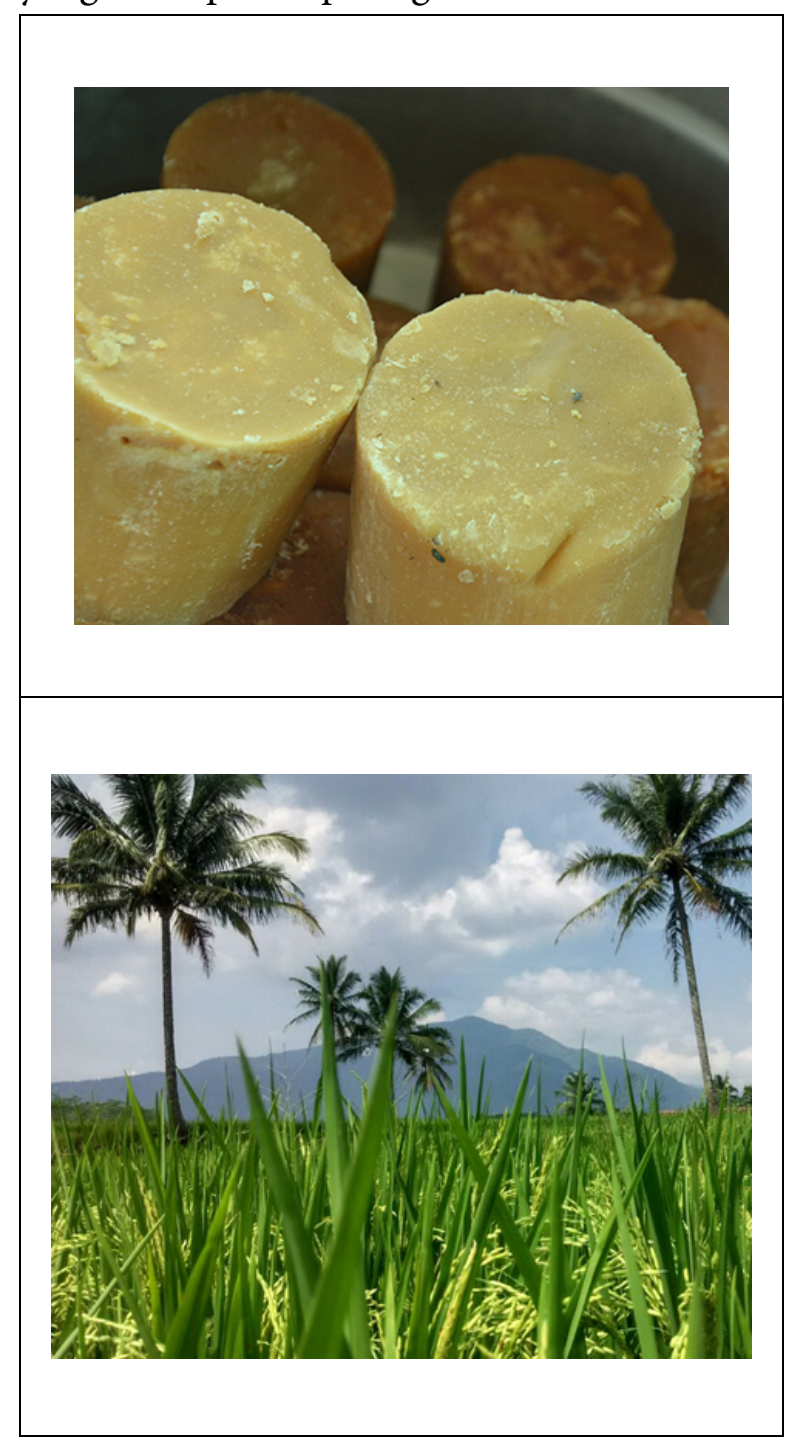

Gambar 9 Color Mood Tradisional.

( Sumber: dokumetasi peneliti)

Warna-warna yang akan diterapkan dalam desain kemasan adalah:
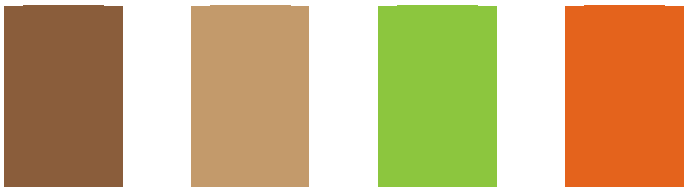

Warna Coklat identik dengan warna dasar burayot hasil dari campuran bahanbahan dan proses penggorengan. Sentuhan warna hijau sebagai warna alam pedesaan, dimana Burayot berasal dari Leles Garut. Untuk menambah kontras diberi warna pendukung yaitu jingga.

Sementara untuk citra modern, casual dan manis akan muncul visual yang berwarna gelap namun memiliki komposisi tidak berat, seperti yang ditampilkan pada gambar 10 .

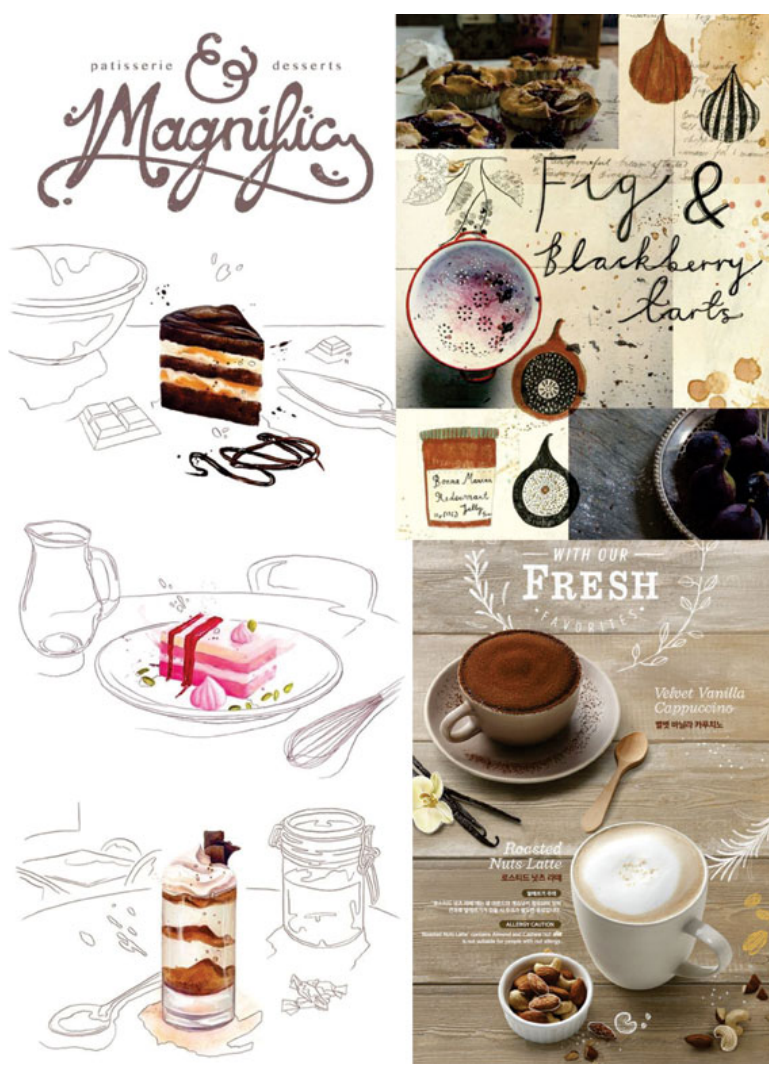

Gambar 10 Color Mood Modern. (sumber : berbagai sumber)

Warna-warna yang akan diterapkan dalam desain kemasan adalah:
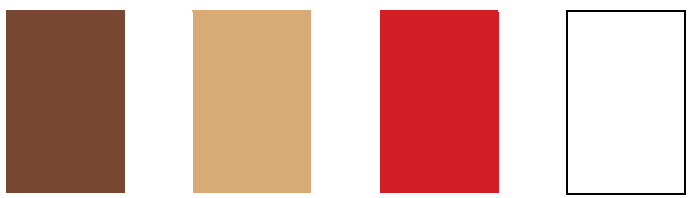
Warna Coklat masih identik dengan warna dasar burayot dan dikombinasikan dengan warna coklat muda. Sedangkan penambahan warna merah agar memberi kesan kontras dan lebih terlihat modern. Untuk memberi kesan ringan diberi warna putih.

\section{ALTERNATIF DESAIN LABEL KEMASAN}

Dari berbagai sumber gagas yang telah dijabarkan, maka muncullah beberapa alternatif desain untuk grafis kemasan.

\section{A. Logotype}

Berdasarkan referensi logotype yang telah dikumpulkan, muncul beberapa alternatif logotype yang telah dibuat, seperti yang ditampilkan di gambar 11 dan gambar 12.

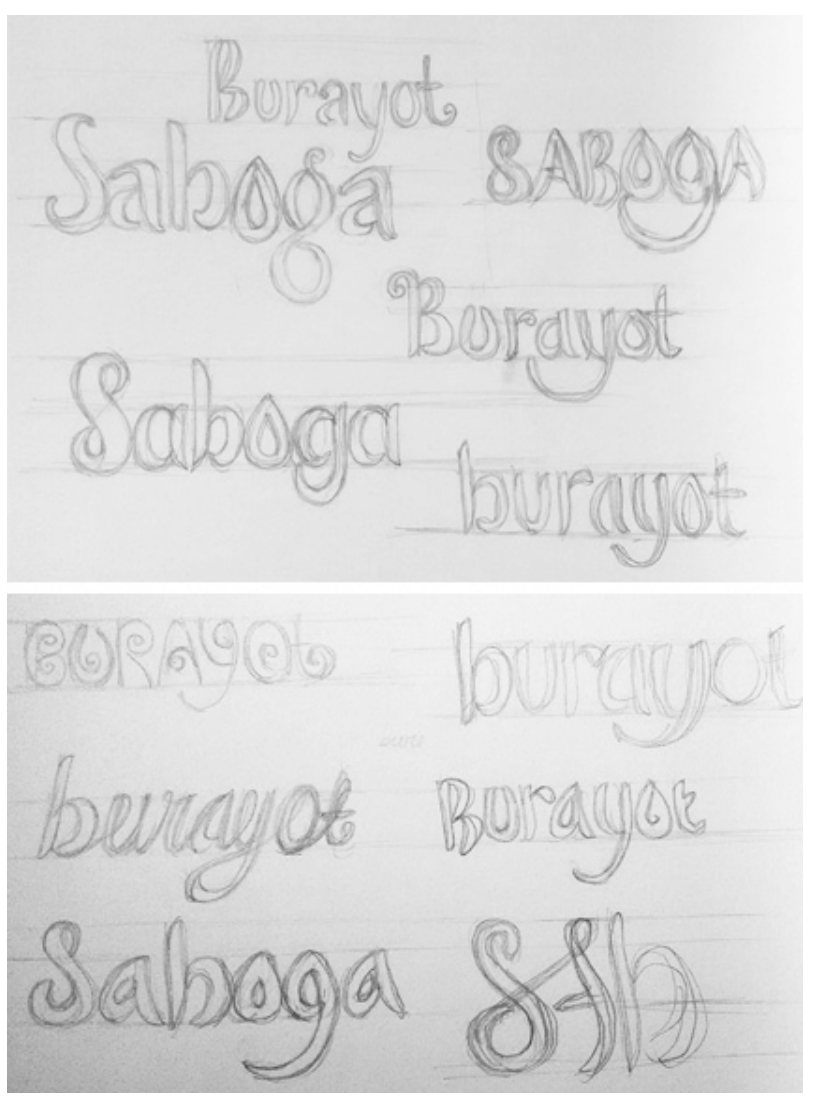

Gambar 11 Alternatif logotype 1

( Sumber: dokumentasi peneliti)

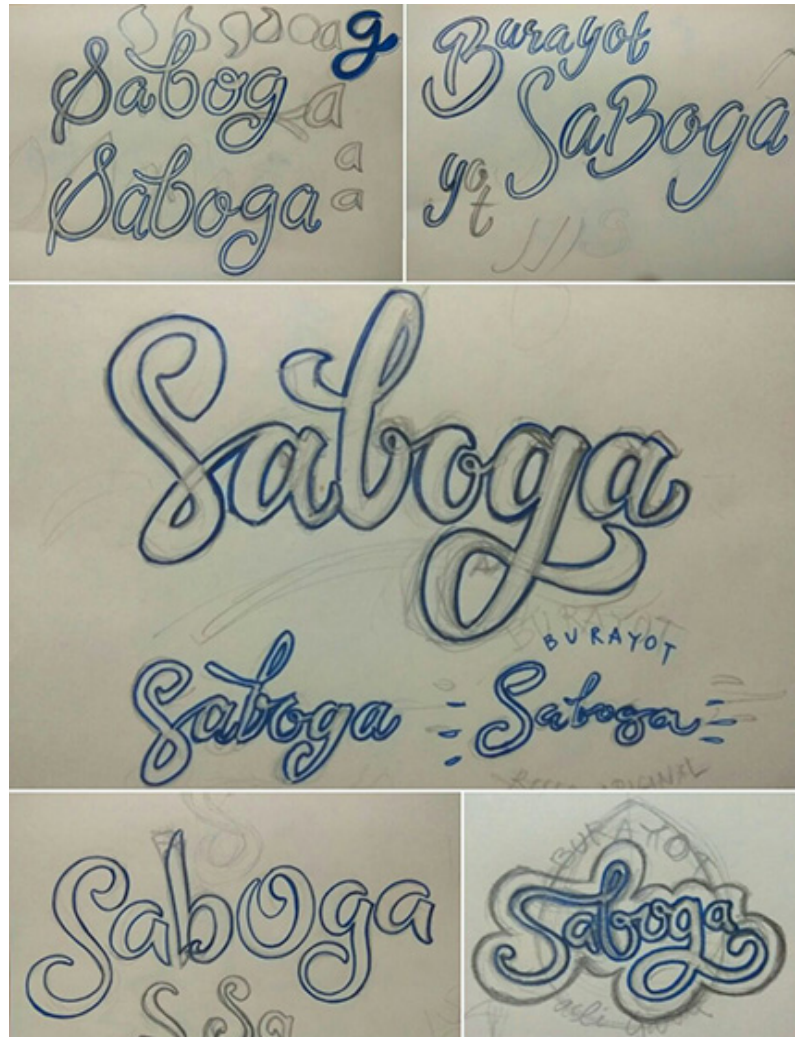

Gambar 12 Alternatif logotype 2.

(Sumber: dokumentasi peneliti)

B. Maskot

Berdasarkan sumber gagas perempuan Sunda yang telah dikumpulkan, maka muncul beberapa alternatif maskot, seperti yang ditampilkan pada gambar 13. Citra yang telah dikonsepkan adalah tradisional, manis dan santai. Pemilihan karakter dan penggayaan perupaan juga disesuaikan dengan citra tradisional, manis, dan santai. 


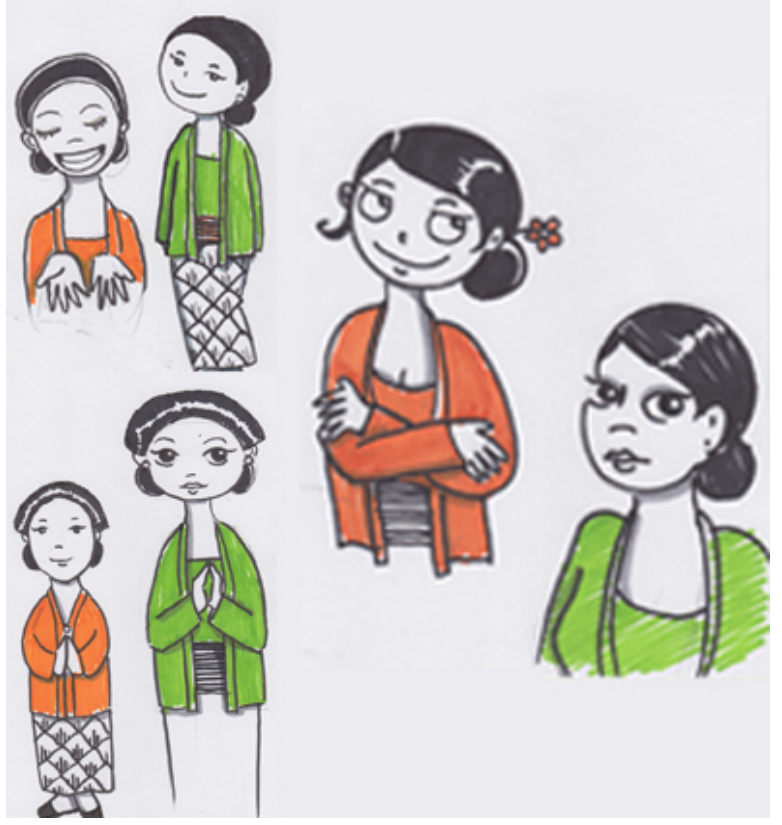

Gambar 13 Alternatif maskot perempuan Sunda. (sumber : dokumentasi peneliti)

\section{Alternatif grafis kemasan}

Ada dua alternatif penggayaan untuk grafis kemasan, gambar 14 sampai gambar 15 menggunakan maskot perempuan Sunda, sementara gambar 16 menggunakan teknik fotografi untuk menampilkan perupaan pada kemasan.

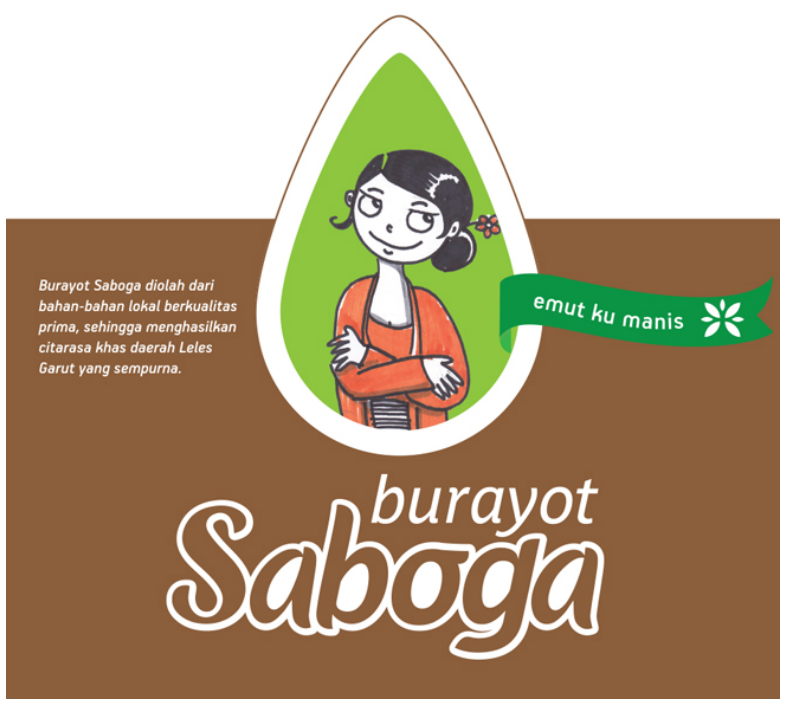

Gambar 14 Alternatif grafis kemasan 1 (Sumber: dokumentasi peneliti)

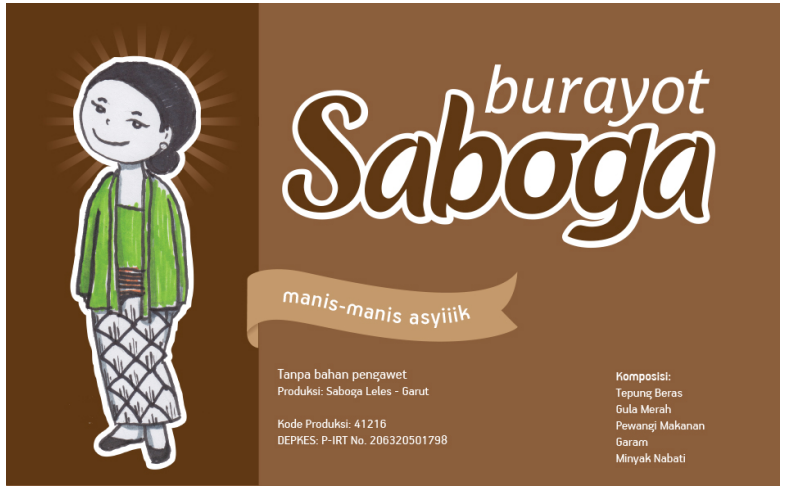

Gambar 15 Alternatif grafis kemasan 2 ( Sumber: dokumentasi peneliti)

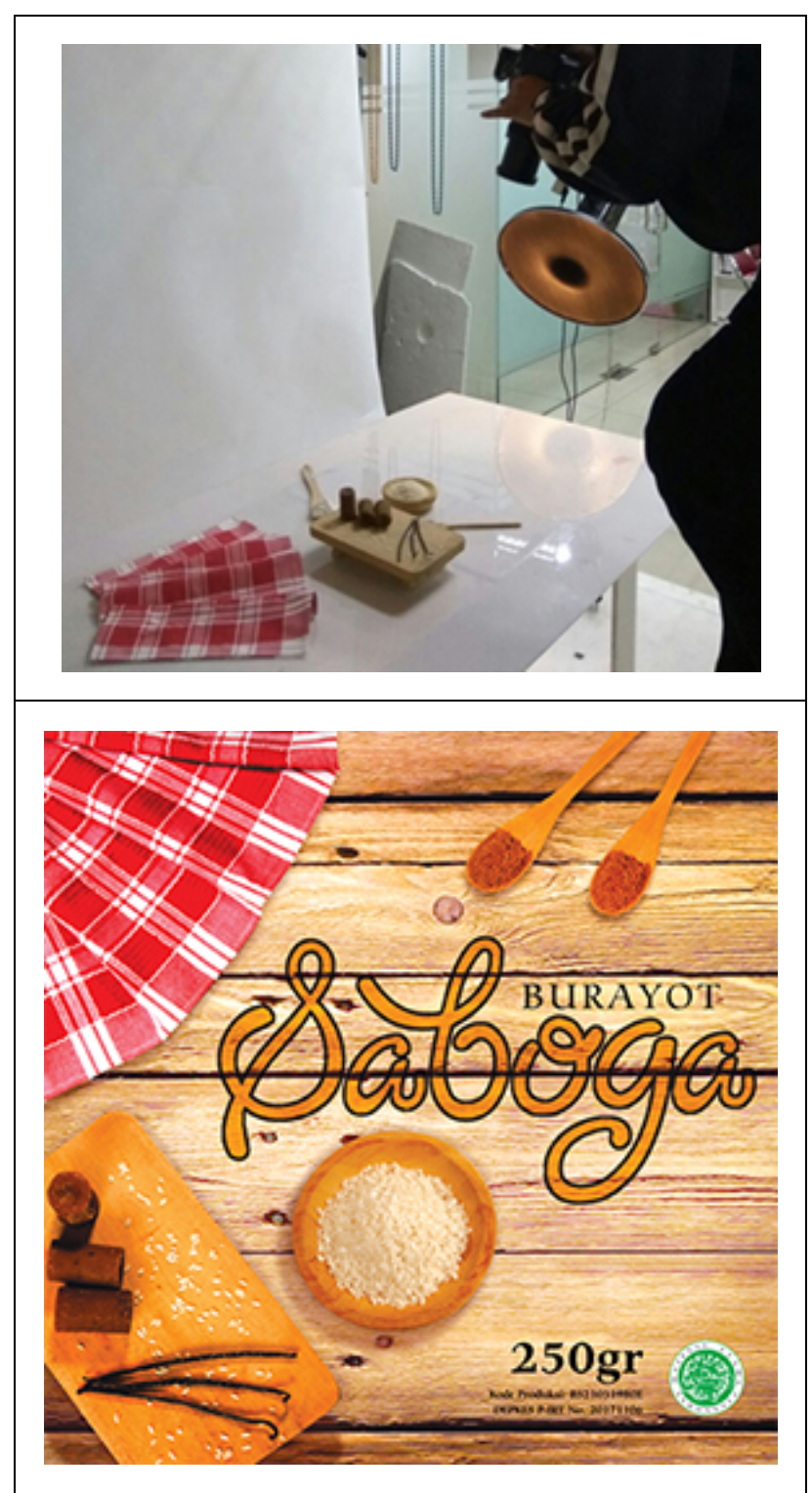

Gambar 16 Alternatif Grafis Kemasan 4 (Sumber: dokumentasi peneliti) 


\section{IMPLEMENTASI DAN PENGUJIAN}

Kendala dalam penerapan penganan burayot ke dalam bahan kertas berkaitan dengan minyak yang meresap ke area kertas. Umumnya makanan yang digoreng akan memiliki kandungan minyak yang tinggi dan burayot termasuk ke dalam kategori tersebut. Berdasarkan ujicoba makan diputuskan, material kertas belum dapat digunakan karena dapat merusak struktur dan terlihat menjadi kotor oleh rembesan minyak.

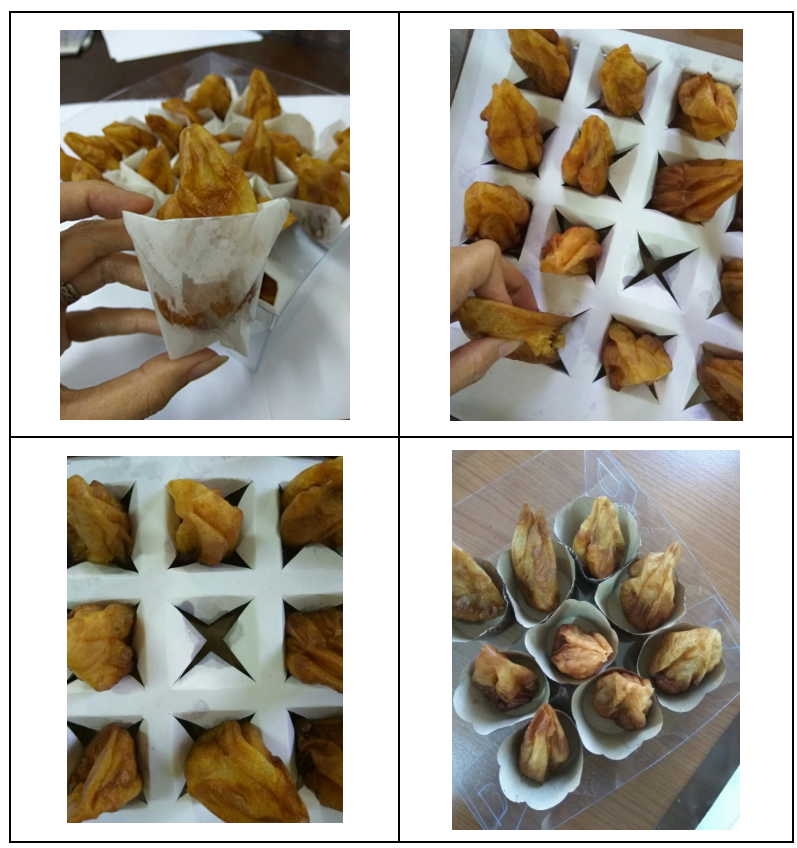

Gambar 17 Pengujian Struktur Wadah Dalam ( Sumber: dokumentasi peneliti)

Material yang aman digunakan agar burayot tetap bertahan dalam 2 (dua) minggu adalah plastik. Produk plastik menjadi pilihan produsen penganan burayot selain mampu menahan resapan minyak juga dapat memperlihatkan isinya.

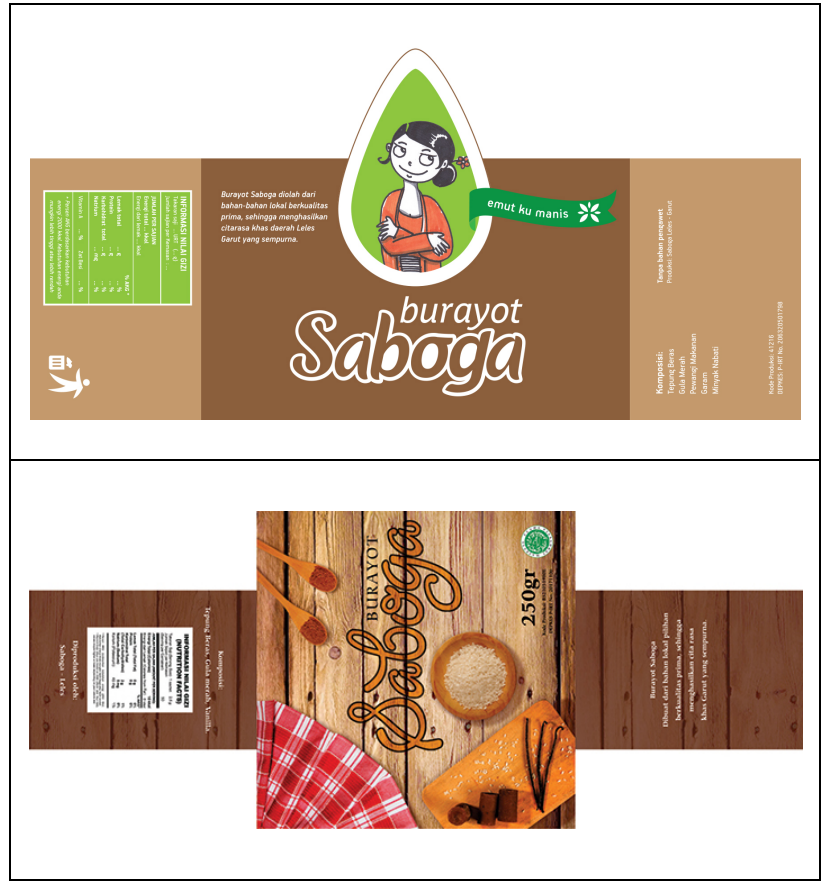

Gambar 18 Gambar Alternatif Label Terpilih (Sumber: dokumentasi peneliti)

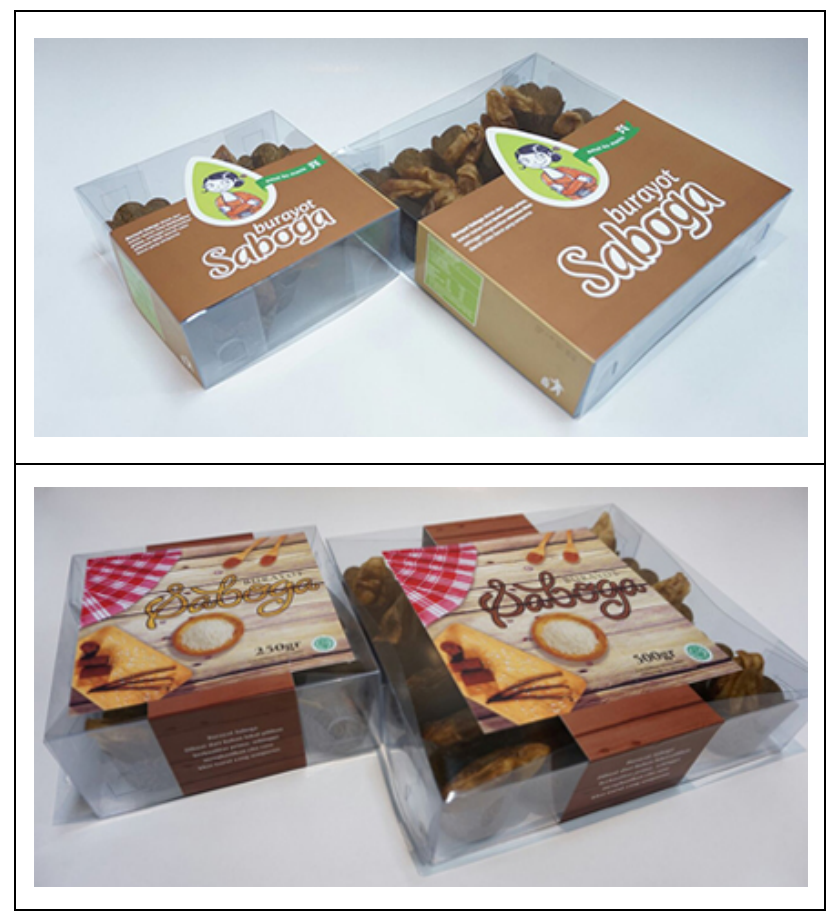

Gambar 19 Hasil akhir tampilan kemasan burayot. (Sumber: dokumentasi peneliti) 


\section{DAFTAR PUSTAKA}

\section{Buku:}

[1] Ambrose, Gavin; Harris, Paul. 2011. Packaging the Brand. Switzerland. AVA Publishing SA

[2] Ambrose, Gavin; Harris, Paul. 2011. Layout. Switzerland: AVA Publishing SA

[3] Andrianto, Tuhana Taufiq. 2008. Tip Memilih Makanan Produk Industri: Kenali Bahayanya Terhadap Kesehatan. Yogyakarta: Universitas Atma Jaya Yogyakarta

[4] Julianti, Sri. 2014. The Art of Packaging. Jakarta: Gramedia Pustaka Utama

[5] Klimchuk, Marianne Rosner; Krasovec, Sandra A. 2007. Desain Kemasan: Perencanaan Merek Produk yang Berhasil Mulai dari Konsep sampai Penjualan. Jakarta: Erlangga

[6] Sihombing, Danton. 2003. Tipografi dalam Desain Grafis. Jakarta: Gramedia Pustaka

[7] Wahyudi, Nanang; Sonny Satriono. 2017 Mantra Kemasan Juara:Elex Media Komputindo. Jakarta

[8] Julianti, Sri. 2017. A practical Guide To Flexible Packaging. Material,Teknologi dan Aplikasi. PT Gramedia Pustaka Utama

[9] _.2012. Undang-Undang Republik Indonesia Nomor 18 Tahun 2012 Tentang Pangan.

[10]_.2016. Peraturan Kepala Badan Pengawas Obat dan Makanan Republik Indonesia Nomor 12 Tahun 2016 Tentang Pendaftaran Pangan Olahan. BPOM Republik Indonesia

\section{Internet:}

http://kitlv-media.nl

http://www.packagingoftheworld.com/2016/s amhoud-food.html?m=1

http://www.behance.net/gallery/24604903/Ear

ly-Rise-Baking-Co

http://www.shutterstock.com/image-

vector/retro-set-label-bread-bakery-old-

284555405

https://dribbble.com/shots/356082-World-

Harvest-Offering-

Logo list=popular\&offset $=106$

https://pinthemall.net/pin/53af680c4bd2e

(diakses terakhir Juli 2017) 